\title{
Laboratory Indicators and Some Considerations in Albanian Patients with Beta Thalassemia Major and Sickle Cell Disease
}

\author{
Manika Kreka', Eleni Nastas ${ }^{2}$, Etleva Refatllari' ${ }^{1}$, Alma Idrizi' ${ }^{1}$, Vjollca Shpata ${ }^{1}$, Bledi Kreka$^{2}$, \\ Anila Godo ${ }^{1}$ \\ ${ }^{1}$ University of Medicine, Tirana, Albania \\ ${ }^{2}$ University Hospital Center "Mother Teresa", Tirana, Albania \\ Email: manika.kreka@umed.edu.al
}

How to cite this paper: Kreka, M., Nastas, E., Refatllari, E., Idrizi, A., Shpata, V., Kreka, B. and Godo, A. (2022) Laboratory Indicators and Some Considerations in Albanian Patients with Beta Thalassemia Major and Sickle Cell Disease. Journal of Biosciences and Medicines, 10, 141-149. https://doi.org/10.4236/jbm.2022.101011

Received: December 19, 2021

Accepted: January 23, 2022

Published: January 26, 2022

Copyright $\odot 2022$ by author(s) and Scientific Research Publishing Inc. This work is licensed under the Creative Commons Attribution International License (CC BY 4.0).

http://creativecommons.org/licenses/by/4.0/

\begin{abstract}
Haemoglobinopathies are very serious clinical conditions caused by genetic mutations. They belong to autosomal recessive disorders and the most frequent genetic inherited diseases seen, specifically and above all among Mediterranean countries. Thalassaemia syndromes (included Beta Thalassaemia and Sickle Cell Disease) have been the first diagnosed diseases since in intrauterine life using reccombinant DNA techniques. So, the better understanding of their pathophysiology has given a spectacolar improvement and a considerable impact on these conditional managements. Every year there are nearly 300,000 children born with haemoglobinopathies globally, and there are 60,000 - 70,000 children with Beta Thalassemia among them. Nowadays in Albania like everywhere, there is a significant increase of survival in these patients. As a result of life longevity and improvement of patients life quality, we can see that these patients may suffer from other concomitant illnesses. In our country, there are registered approximately 500 patients with haemoglobinopathies. We studied 50 pediatric patients at random ranging from age 2 until 18 years old. We excluded other pathologies among them. We found high values of biochemical indicators in blood ( $\mathrm{Ca} \mathrm{15-3}$ was found elevated in $75 \%$ of our patients, Lactate Dehydrogenases was found elevated in $70 \%$ of cases, Indirect Bilirubin was found elevated in $66 \%$ of cases). All three parameters are indicators of hemolysis. We found a correlation between high values of Ca 15-3 marker and high levels of LDH, Indirect Bilirubin and low level of hemoglobin $(\mathrm{p}<0.05)$. Ca $15-3$ is much elevated among patients non regularly transfused and in those who take an unsufficient amount of blood. Continuous monitoring of these biochemical parameters is going to help in the more effective follow up of patients with haemoglobinopathies.
\end{abstract}




\section{Keywords}

TM-Thalassemia Major, TI-Thalassemia Intermedia, SCD—Sickle Cell

Disease, TSCD—Thalassemia-Sickle Cell Disease, LDH_Lactate

Dehydrogenases, Ca 15-3-Tumor Marker, IB-Indirect Bilirubin,

PRBC-Pure Red Blood Cells, Apoptosis-Programmed Death of the Cell

\section{Introduction}

Haemoglobinopathies ( $\beta$-Thalassemia and Sickle Cell Disease) refer to a heterogeneous inherited group of hemoglobin, characterized by a quality or quantity deficit of hemoglobin synthesis. Haemoglobinopathies are part of autosomal recessive diseases, the most prevalent genetic blood diseases in the world [1]. People affected by these types of diseases suffer from a chronic hemolytic anemia throughout their life, and to this aim, they need permanent regular blood transfusion therapy as a crucial treatment.

Statistical data from WHO registry show that there are more than 70 million carriers of these pathologic genes, about 10 million are born and live in Europe, mainly in area surrounded by Mediterranean Sea. According to Thalassemia International Federation, there are approximately 500,000 patients with Beta Thalassemia registered in treatment and follow-up. There are more than 100,000 patients suffering from Sickle cell Disease worldwide (data are mainly collected from USA database) [2].

It is estimated that nearly $7.1 \%$ of the population is a carrier of any type of haemoglobinopathies in Albania. Currently there are at least 530 patients (children and adults) who have been diagnosed and in treatment in Albania. The majority of our patients are diagnosed with Beta Thalassemia Major and Intermediate (84.5\%) and the rest (15.5\%) are diagnosed with Sickle Cell Disease. There is no difference related to sex distribution. Regarding genetic mutations, it is well-known that there are around 300 genetic mutations of $\beta$-thalassemia. In Mediterranean population, there are known approximately 20 most seen mutations (12 cause decrease of beta globin chain synthesis and 8 out of them seem to be responsible for absence of beta globin chain [3].

There are a lot of clinical manifestations which vary from mild anemia to severe one, which could be fatal if untreated systematically [4]. Patients with these anemias during their treatment with blood intake, manifest high ferritin levels in blood, developing iron overload in major organs. This is not only due to frequent transfusions but also to increased intestinal absorption, because of the main disease. Iron overload causes organ damages like: cardiac, hepatic, endocrine dysfunction, but also fatal loss of life as a consequence of non treatment.

During these last decades, there is a significant improvement in patients with haemoglobinopathies who are in treatment, globally and in our country as well. As a result of this improvement these patients can live longer and as a consequence they can manifest some accompanying diseases like other people aging [2]. To this 
point, we confirm that till now blood transfusions with pure red blood cells are the crucial treatment accompanied by iron chelation therapy to treat iron overload. Oral iron chelation therapy nowadays are the remarkable achievement in patients treatment. Without treatment, $\beta$-thalassaemia major is lethal within the first decade of life due to the complex pathophysiology, which leads to wide clinical manifestations. Current clinical management for these patients depends on repeated transfusions followed by iron-chelating therapy. Several novel approaches to correct the resulting $\alpha / \beta$-globin chain imbalance, treat ineffective erythropoiesis and improve iron overload are currently being developed. Up to now, the only curative treatment for $\beta$-thalassemia is haematopoietic stem-cell transplantation, but this is a risky and costly procedure. Gene therapy, gene editing and base editing are emerging as a powerful approach to treat this disease. In $\beta$-thalassaemia, gene therapy involves the insertion of a vector containing the normal $\beta$-globin or $\gamma$-globin gene into haematopoietic stem cells to permanently produce normal red blood cells [5]-[11].

Many drugs are under development in order to decrease frequency of blood transfusions and gene therapy might be the solution for patients with haemoglobinopathies (5). Diagnosis of these pathologic conditions should be confirmed by laboratory examinations (Complete blood count, Hemoglobin Electrophoresis, and above all gene mutations).

But on the other hand there are of great value and importance, monitoring of these laboratory indicators we decided to evaluate, in order to assist our patient in our clinical patients and to improve their treatment.

Hemolysis is the characteristic and crucial manifestation and it could be measured through some indicators.

One of them is Indirect Bilirubin. It is a fraction of total bilirubin, which is elevated in different hemolysis and in some hepatic glucoronate diseases. It is an indicator which reflects erythrocyte destruction. The mean value of Indirect Bilirubin is less than $1 \mathrm{mg} / \mathrm{dl}(0.5-0.7 \mathrm{mg} / \mathrm{dl})$.

Lactate Dehydrogenase is the enzyme of Glycolysis, which catalyses the conversion of lactate to pyruvate and vice versa. The mean normal value of this enzyme in blood is: 200 - $370 \mathrm{UI} / \mathrm{L}$.

It is known that there are 5 subtypes of LDH: LDH1, LDH2, LDH3, LDH4, LDH5.

The most important isoenzymes are LDH1 and LDH2, which are present in cardiac muscle, renal tissue and erythrocytes, areas where the tissues are fully oxygen provided as a consequence of oxidative metabolism.

These enzymes are present in high levels in Myocardial Infarct, Megaloblastic Anemia, Hemolytic Anemia. The other LDH isoenzymes are present in high levels in acute hepatitis, cancer diseases, muscular diseases, hypoxia etc.

Tumor marker Ca 15-3 is a glycoprotein, which is mainly produced in epithelial cells of human organism. Normal value of this marker belongs to this interval $9-31 \mathrm{U} / \mathrm{ml}$. It is found elevated mainly in malignant diseases like Breast Carcinoma . It is really helpful in monitoring patients who are in treatment with 
chemotherapy. It serves as an indicator for these patient's follow-up. But high blood levels of $\mathrm{Ca}$ 15-3 we can find in other benign circumstances like: geriatric patients, some collagen diseases, in pregnancy, some pathologies accompanied with serous articular effusions and hemolytic anemia's [6].

To this aim, in order to evaluate how much these indicators stand to our patients, we tried to show the correlation between these hemolytic data in our patients with hemolytic anemia.

\section{Methodology and Materials}

We studied at random 50 patients with haemoglobinopathies (Beta Thalassemia Major and Sickle Cell Disease) who are in follow up near by our clinic. We got Informed Consent of them.

Among them the distribution according to diagnosis is divided into $40 \mathrm{pa}-$ tients with Beta Thalassemia Major and 10 patients with Sickle Cell Disease. It was excluded other pathologic condition. There were 23 males and 27 females. They all belonged to the interval age $2-18$ years old. It was collected values in blood for: Ca15-3. LDH, Indirect Bilirubin, pre-transfusion level of Hemoglobin. For all of them were excluded all accompanying diseases which can be connected to any elevated biological marker (mentioned above).

\section{Results}

As it is seen in Figure 1, the majority of patients in study (62\%) had pre-transfusion level of hemoglobin less than $8.5 \mathrm{~g} / \mathrm{dl}$, and only 19 patients out of them $(32 \%)$ had this pre-transfusion hemoglobin level above $9.5 \mathrm{~g} / \mathrm{dl}$.

As it is seen in Figure 2, the majority of patients have IVS-I-110 $(G>A)$, which is a moderate $\beta+$ mutation, less severe of Codon 39 .

As it is seen from Table 1 and Figure 1, both males and females patients manifest very low pre-transfusion hemoglobin levels due to many factors (severe hemolysis due to severity of mutation itself, lack of blood donation in some days especially summer, rare antigenic structures of Rhesus blood groups).

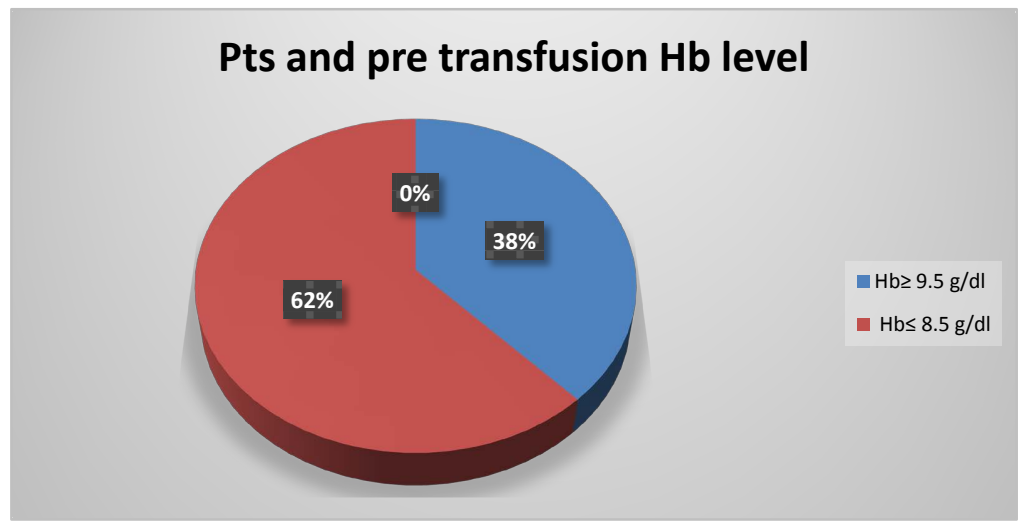

Figure 1. Distribution of patients according to pre-transfusion hemoglobin's level. 
No of Patients and mutation'type

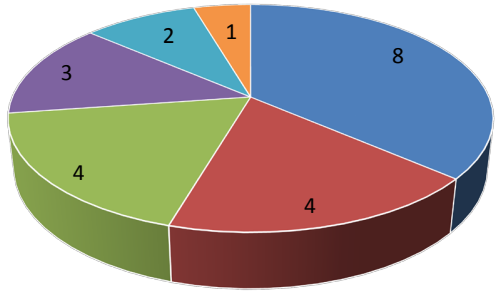

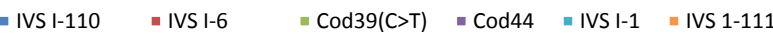

Figure 2. The type of mutations distributed amongst Albanian patients.

Table 1. The mean value of pre-transfusion hemoglobin level.

\begin{tabular}{ccccc}
\hline & Sex & Number of patients & Mean value & S.D. \\
\hline $\mathrm{Hb}$ & Male & 27 & 7.64 & 1.00 \\
& Female & 23 & 7.65 & 1.07 \\
\hline
\end{tabular}

In Table 2, it is shown that patients with genotype $\mathrm{Cd} 39$, have low hemoglobin level compare to total number of patients (it is statistically significant (Independent sample $t$ test statistic $=1.954 \mathrm{p}=0.03$ ). Therefore, they need more units of blood (PRBC) in order to cope with a qualitative life (Independent sample $t$ test statistic $=2.33 \mathrm{p}=0.02$ ).

In Figure 3, it is shown that Ca $15-3$ is present in nearly $75 \%$ of patients, compared to $25 \%$ of patients who present normal values.

In Table 3, it is shown that the mean value of $\mathrm{Ca} 15-3$ is a slight higher in males compare to females (47.9 vs 46.4 ).

As it is seen in Figure 4, the majority of patients manifest double and triple $\mathrm{LDH}$ level. The number of patients with normal values is 15 patients, there are 12 patients with double $\mathrm{LDH}$ value and there are 16 patients with triple $\mathrm{LDH}$ value.

In Table 4 is shown that there is a higher $\mathrm{LDH}$ value in females compared to males.

It is used Student test for two separated variables. In Table 5, it is shown that there is no significant statistical difference between patients (male/female) for all variables studied in the Confidence Interval 95\%.

In Table 6, it is shown that there is a significant correlation between high levels of Ca 15-3 and high levels of $\mathrm{LDH}$, Indirect Bilirubin and the low level of pre-transfusion hemoglobin $(\mathrm{p}<0.05)$.

Tumor marker Ca $15-3$ is much elevated in patients non-transfused accordingly to their need.

In Table 7, it is shown that there is a strong correlation between LDH and Indirect Bilirubin ( $\mathrm{p}$ value $=0.03$ ). This confirms the strength of hemolysis among these laboratory data. 
In Table 8, it is shown Pearson Correlation between Ca 15-3, LDH, Indirect Bilirubin and Hemoglobin.

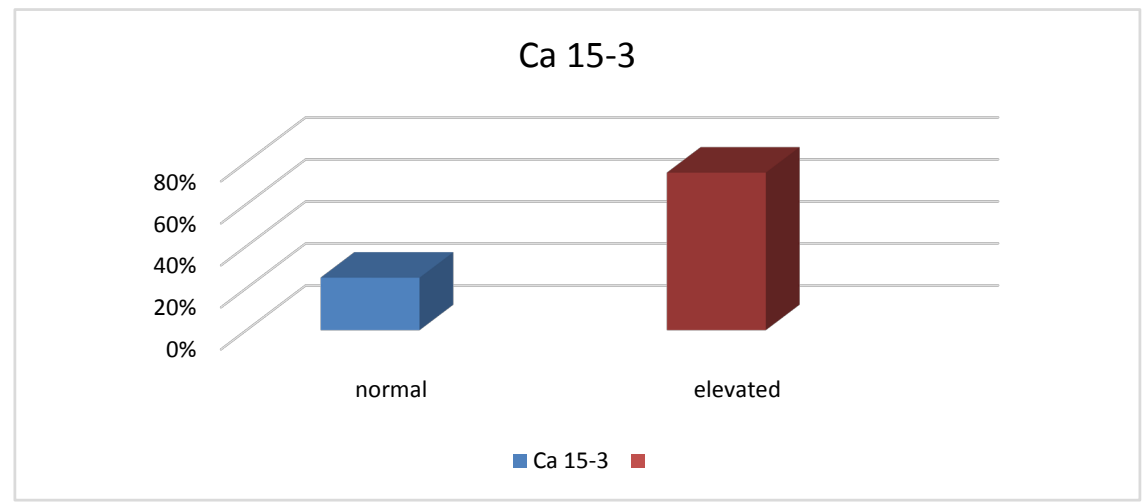

Figure 3. Ca 15-3 indicator in patients with haemoglobinopathies.

\section{LDH AND PATIENTS}

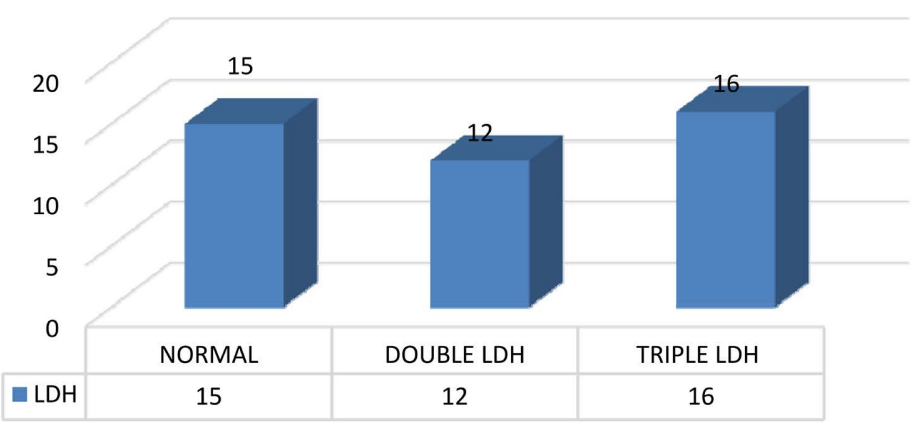

Figure 4. Number of patients according to LDH level measured.

Table 2. Codon 39 mutation, Hemoglobin level and quantity of blood needed.

\begin{tabular}{ccccc}
\hline & Patients with Cd 39 mutation & No of patients & $\mathbf{t}$ & $\mathbf{p}$ \\
\hline $\mathrm{Hb}(\mathrm{g} / \mathrm{dl})$ & $8.1(0.9)$ & $8.5(0.7)$ & 1.9 & 0.03 \\
$\mathrm{PRBC}(\mathrm{n} / \mathrm{mon}$ th) & $3.8(1.1)$ & $3.1(1.1)$ & 2.3 & 0.02 \\
\hline
\end{tabular}

PRBC-Pure Red Blood Cells.

Table 3. The mean value of Ca 15-3 in patients with haemoglobinopathies.

\begin{tabular}{ccccc}
\hline & Sex & Number of patients & Mean & S.D. \\
\hline Ca $15-3$ & Male & 27 & 47.09 & 17.6 \\
& Female & 23 & 46.40 & 17.4 \\
\hline
\end{tabular}

Table 4. The mean value of LDH in patients with haemoglobinopathies.

\begin{tabular}{ccccc}
\hline & Sex & Number of patients & Mean & S.D. \\
\hline \multirow{2}{*}{ LDH } & Male & 27 & $\mathbf{6 8 6 . 7}$ & 419.4 \\
& Female & 23 & $\mathbf{8 6 4 . 6}$ & 474.4 \\
\hline
\end{tabular}


Table 5. The mean Indirect Bilirubin level in patients with haemoglobinopathies.

\begin{tabular}{lcccc}
\hline & Sex & Number of patients & Mean value & S.D. \\
\hline Indirect Bilirubin & Male & 27 & 1.85 & 0.9 \\
& Female & 23 & 2.7 & 2.2 \\
\hline
\end{tabular}

Table 6. Student test used to compare hemolityc indicators.

\begin{tabular}{ccc}
\hline & t value & $\mathrm{p}$ \\
\hline Ca 15-3 & 0.137 & 0.89 \\
LDH & -1.408 & 0.16 \\
Indirect Bilirubin & -1.998 & 0.05 \\
Hemoglobin & -0.04 & 0.96 \\
\hline
\end{tabular}

Table 7. Pearson Correlation for LDH.

\begin{tabular}{ccc}
\hline & & Indirect Bilirubin \\
\hline LDH & Coefficient of Correlation & 0.295 \\
& $\mathrm{p}$ value & 0.03 \\
\hline
\end{tabular}

Table 8. Pearson Correlation for Ca 15-3, LDH, Indirect Bilirubin and Hemoglobin.

\begin{tabular}{ccccc}
\hline & & LDH & Indirect Bilirubin & Hemoglobin \\
\hline Ca15-3 & Coefficient of Correlation & 0.54 & 0.43 & 0.27 \\
& p value & $\mathbf{0 . 0 4 8}$ & $\mathbf{0 . 0 4 1}$ & $\mathbf{0 . 0 3 4}$ \\
\hline
\end{tabular}

\section{Discussion}

Our country, Albania is well known for the presence of Beta Thalassemia Major and other haemoglobinopathies (since it is located in Mediterranean area).

Haemoglobinopathies, a major scientific problem worldwide, is fully recognized and treated in our country too.

Blood transfusions and oral chelation therapy is available and the life longevity is expanded in the last decades.

In this modest study we introduced some data of haemoglobinopathies in our patients.

We evaluated some hemolytic indicators in 50 patients (40 out of patients studied were diagnosed with Thalassemia Major and 10 out of them were diagnosed with Sickle Cell Disease). Frequencies of the most common $\beta$-thalalleles (IVS-I-110, Codon 39, IVS-I-6) which are similar to those of the surrounding Balkan and Mediterranean countries [7]. The IVS-I-110 mutation has its highest frequency in the east Mediterranean region (Cyprus, Lebanon, Greece, Republic of Macedonia, Turkey), whereas the codon 39 mutation is found mainly in the west (Sardinia, Sicily, Spain) [8] [9].

Studying the correlation between type of genetic mutation and some laboratory data as well as need for transfusion has shown with some management data 
of this type of Thalassaemia. The genotype Codon 39 is a severe mutation (the third as per percentage among our patients). The patients in this genotype have lower pre transfusion hemoglobin compare to others (Hemoglobin $8.1 \mathrm{~g} / \mathrm{dl}$ compare to hemoglobin $8.5 \mathrm{~g} / \mathrm{dl}$ in the total of patients). This is statistically signficant $(\mathrm{t}=1.954, \mathrm{p}=0.05)$.

These patients need more amount of blood compare to total of patients and this is statistically significant: $t=2.33$ and $\mathrm{p}=0.02$.

The mean number of pure red blood cells per month is 3.8 units compare of the total of patients' need. All these results are similar with those of literature, especially data reported from Mediterranean countries [10].

The biological indicators which were evaluated are: Ca 15-3, LDH, Indirect Bilirubin and level of pre transfusion hemoglobin. Our data collected were fully compatible with data in up to date literature, which stresses that hemolysis is always present in our patients [3] [4] [11].

The tumor marker $\mathrm{Ca} 15-3$ is highly elevated in our patients in $75 \%$ of our patients (more than $25 \%$ of Upper Normal Limit). The mean value was $47.09 \mathrm{U} / \mathrm{ml}$ in males and $46.40 \mathrm{UI} / \mathrm{ml}$ in females.

The majority of patients presented higher LDH level (70\%). So, 15 patients had normal LDH values, on the other hand 35 patients had 2 - 3 times higher values of $\mathrm{LDH}$.

The mean value of $\mathrm{LDH}$ was $686.7 \mathrm{UI} / \mathrm{L}$ in males and 864.6 UI/L in females. Indirect Bilirubin was considerable high in this population due to present hemolysis. So, the mean Indirect Bilirubin was $2.7 \mathrm{~g} / \mathrm{dl}$ in females and $1.85 \mathrm{~g} / \mathrm{dl}$ in males $(\mathrm{S} . \mathrm{D}=2.2 / 0.9)$.

Amongst our patients the mean value of hemoglobin was 7.64 in males and 7.65 in females.

Using Student test for two independent samples, we understood that there is no significant statistical difference between males and females for all variables studied in Confident interval 95\%.

It does exist a good correlation between high values of $\mathrm{Ca}$ 15-3 and the high values of LDH, Indirect Bilirubin and low level of hemoglobin $(\mathrm{p}<0.05)$. This important tumor marker $\mathrm{Ca} 15-3$ is usually elevated between patients with hemoglobinopathies. This fact is supposed to be connected to ineffective erythropoiesis of Bone Marrow (6). This marker is released as a result of augmented erythroblasts apoptosis. Hemolysis always present is supported scientifically with high values of Lactate Dehydrogenases and Indirect Bilirubin, and low levels of hematocrit and hemoglobin in blood's patients [10].

To the end we may stress that all these biologic markers are used by our medical staff in order to better treat and support our patients in relation to their clinical presentation which is strongly represented with these biologic markers.

To date blood transfusion remains the gold standard of treatment and a cure to suppress the hemolysis which in some cases seems to be severe and should be greatly evaluated. So a close monitoring, clinically and laboratory allows us to a better treatment of our patients, tailoring the frequency of transfusions. 
Voluntary blood donation has to be encouraged among population, in order to cover patients need.

\section{Conflicts of Interest}

The authors declare no conflicts of interest regarding the publication of this paper.

\section{References}

[1] Borgna-Pignati, C., et al. (1999) Survival and Disease Complications in Thalassaemia Major. Annals of the New York Academy of Sciences, 850, 227-231. https://doi.org/10.1111/j.1749-6632.1998.tb10479.x

[2] Weathreall, D.J. and Clegg, J.B. (2001) Inherited Haemoglobin Disorders, an Increasing Global Health Problem. Bulletin of the World Health Organisation, Vol. 79, 704-712.

[3] Antoniou, M. and Grosveld, F. (1999) Genetic Approaches for Therapy for the Haemoglobinopathies. In: Fairbairn, L.J. and Testa, N.G., Eds., Blood Cell Biochemistry, Springer, Boston, Vol. 8, 219-242.

https://doi.org/10.1007/978-1-4615-4889-8_8

[4] Wonke, B. (2001) Clinical Management of Beta Thalassaemia Major. Seminars Hematology, 38, 350-359. https://doi.org/10.1053/shem.2001.27577

[5] Soni, S. (2020) Gene Therapies for Transfusion Dependent $\beta$-Thalassemia: Current Status and Critical Criteria for Success. American Journal of Hematology, 95, 1099 1112. https://doi.org/10.1002/ajh.25909

[6] Kreka, M. (2017) Thalassaemia and Sickle Cell Disease. LAP LAMBERT Academic Publishing, Saarbrucken.

[7] de Angioleti, M., Lacerra, G., Boletini, E., et al. (2002) $\beta$ - and $\alpha$-Globin Genotypes in Albanian Patients Affected by $\beta$-Globin Gene Disorders. Haematologica, 87, 1002-1003.

[8] Babameto-Laku, A., Mitre, A., Berisha, S., Mokini, V. and Roko, D. (2011) Molecular Genetic Characterization of $\beta$-Thalassemia and Sickle Cell Syndrome in the Albanian Population. Balkan Journal of Medical Genetics, 14, 45-50. https://doi.org/10.2478/v10034-011-0017-0

[9] Aessopos, A., Kati, M. and Meletis, J. (2014) Thalassaemia Intermedia Today: Should Patients Regularly Receive Transfusions? Transfusion, 47, 792-800.

https://doi.org/10.1111/j.1537-2995.2007.01192.x

[10] Cappellini, N., Cohen, A., Eleftheriou, A., Piga, A. and Porter, J. (2009) Guidelines for the Clinical Management of Thalassaemia. Thalassaemia International Federation, Nicosia.

[11] Karnon, J., Zeuner, D., Brown, J., et al. (1999) Lifetime Treatment Costs of $\beta$-Thalassaemia Major. Clinical and Laboratory Haematology, 21, 377-385.

https://doi.org/10.1046/j.1365-2257.1999.00262.x 